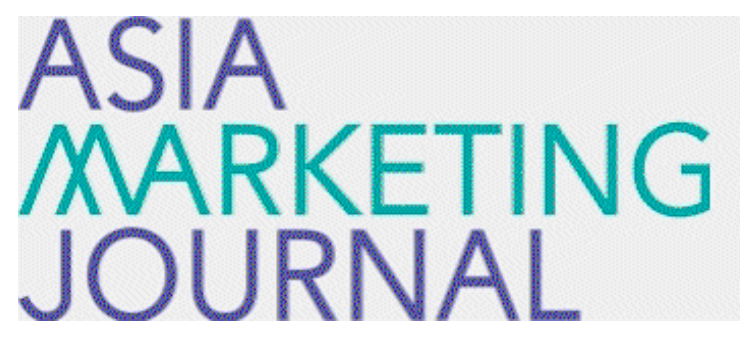

ASIA MARKETING JOURNAL

Volume 14 | Issue 2

Article 2

7-30-2012

\title{
The Effect of Metacognitive Difficulty on Consumer Judgments
}

Se Bum Park

Follow this and additional works at: https://amj.kma.re.kr/journal

Part of the Marketing Commons

\section{Recommended Citation}

Park, Se Bum (2012) "The Effect of Metacognitive Difficulty on Consumer Judgments," Asia Marketing Journal: Vol. 14 : Iss. 2 , Article 2.

Available at: https://doi.org/10.53728/2765-6500.1478

This Article is brought to you for free and open access by Asia Marketing Journal. It has been accepted for inclusion in Asia Marketing Journal by an authorized editor of Asia Marketing Journal. 


\title{
The Effect of Metacognitive Difficulty on Consumer Judgments: The Moderating Role of Cognitive Resources
}

\author{
Se-Bum Park ${ }^{*}$
}

Individuals often make their judgments on the basis of the ease or difficulty with which information comes to mind (for reviews, see Greifeneder. Bless, and Pham 2010: Schwarz 1998. 2004). Recent research, however, has documented that variables known to determine the degree of cognitive resources invested in information processing such as personal relevance (Grayson and Schwarz 1999: Rothman and Schwarz 1998), accuracy motivation (Aarts and Dijksterhuis 1999), and processing capacity (Menon and Raghubir 2003) can affect the extent to which individuals draw on metacognitive difficulty in making their judgments.

The primary aim of this research is thus to investigate whether individuals with substantial cognitive resources or those with lack of cognitive resources are more likely to draw on metacognitive difficulty when making their product evaluations. The findings from two laboratory experiments indicate that individuals who perceive a greater level of fit between their self-regulatory orientation and temporal construal (Experiment 1), and between their self-construal and the type of product benefit appeal (Experiment 2) are more likely than those who perceive the lack of such fit to evaluate a target product less positively after thinking of many rather than a few positive reasons.

The findings provide supporting evidence for the two-stage backward inference process involved with the effect of metacognitive difficulty on consumer judgments in that consumer judgments based on metacognitive difficulty may require greater cognitive resources than those based on the content of information generated. Also, the current research documents further empirical evidence for the relationship between self-regulatory orientation-construal level fit and cognitive resources such that perceived regulatory-construal level fit can increase consumer willingness to invest cognitive resources into their judgment tasks. Last, the findings can help marketers differentiate purchase situations where asking consumers to think of many positive benefits from purchase situations where asking consumers to think of a few key benefits is relatively more beneficial.

Key words: Metacognitive Difficulty, Cognitive Resource, Regulatory Fit, Two-Stage Backward Inference Process

\footnotetext{
* Assistant Professor of Marketing. School of Business. Yonsei University(seapark@yonsei.ac.kr)
} 


\section{Introduction}

Recent investigations have documented that individuals often make their judgments on the basis of the ease or difficulty with which information comes to mind (for reviews, see Greifeneder. Bless, and Pham 2010: Schwarz 1998, 2004). Schwarz et al. (1991). for example, show that individuals rate themselves as more assertive after recalling six rather than 12 examples of their own assertive behaviors. Similarly, consumers evaluate a target product more positively after thinking of a few rather than many positive reasons (Menon and Raghubir 2003: Wänke et al. 1997). According to Schwarz (2004), metacognitive difficulty can affect judgments particularly when the informational value of metacognitive difficulty is not called into question. For example, when individuals misattribute the causes of metacognitive difficulty in retrieving or processing reasons to external distractions (Schwarz et al. 1991) or features of information presentation format (Wänke, Schwarz, and Bless 1995), they are no longer affected by metacognitive difficulty in making their judgments because the informational value of metacognitive difficulty becomes undermined.

Prior research has also documented that variables known to determine the degree of cognitive resources invested in information processing such as personal relevance (Grayson and Schwarz 1999: Rothman and Schwarz 1998), accuracy motivation (Aarts and Dijksterhuis 1999), and processing capacity (Menon and Raghubir 2003) can affect the extent to which individuals draw on metacognitive difficulty in making their judgments. Rothman and Schwarz (1998), for example, find that males with a family history of heart disease are more likely than those without a family history to perceive greater vulnerability to heart disease after recalling many rather than a few risk-increasing behaviors. Relatedely, individuals under low personal relevance than high personal relevance (Grayson and Schwarz 1999), and those under low accuracy motivation than high accuracy motivation (Aarts and Dijksterhuis 1999) are likely to exhibit greater reliance on metacognitive difficulty in making their judgments. Furthermore, Menon and Raghubir (2003) show that individuals under cognitive constraints are likely to rely on metacognitive difficulty regardless of its perceived diagnosticity. A few notable exceptions, however, do exist. Wänke and Bless (2000) show that individuals under high accuracy motivation tend to evaluate a target product more positively after recalling easy-to-process than difficult-to-process product attributes regardless of the argument quality of those attributes. Also, Tormala, Petty, and Briñol (2002) indicate that individuals under high processing motivation such (e.g., high personal relevance, high need for cognition) are more likely to be negatively affected by metacognitive difficulty because metacognitive difficulty reduces the 
confidence in the information they generated.

Given this seeming discrepancy with regard to the role of cognitive resources in predicting the effects of metacognitive difficulty on judgments, the current research hypothesizes that individuals with greater cognitive resources are more likely than those with lack of cognitive resources to rely on metacognitive difficulty because cognitive resources are required for interpreting the informational value of or the meanings associated with metacognitive difficulty experienced. To test this hypothesis, the current research first conceptualizes perceived fit between self-regulatory orientation and temporal construal (Experiment 1) and between self-construal and the type of product benefit appeal (Experiment 2) as the availability of cognitive resources because perceived fit can increase motivational intensity (Idson, Liberman, and Higgins 2000). cognitive resources available (Aaker and Lee 2001: Worthy, Maddox, and Markman 2007), and cognitive persistence (Hong and Lee 2005). Accordingly. individuals who perceive fit between their self-regulatory orientation and temporal construal and between self-construal and the type of product benefit appeal are more likely than those who do not perceive such fit to bring their full cognitive resources to process both the content of information and metacognitive difficulty associated with information processing.

The remainder of this research is organized as follows: The current research begins by summarizing previous literature on the moderating effects of cognitive resources in determining the effect of metacognitive difficulty on judgments in order to build a relevant theoretical foundation. Next, the current research presents two laboratory experiments in which metacognitive difficulty and the availability of cognitive resources are manipulated, and reports the findings that provide convergent evidence in support of the research hypothesis. The current research concludes with a discussion of the implications of the findings for understanding the role of metacognitive difficulty in judgments.

\section{Theoretical Background}

\subsection{The Role of Cognitive Resources in Determining the Effects of Metacognitive Difficulty on Judgments}

Tormala et al. (2002) found that judgments based on metacognitive difficulty required substantial cognitive resources, indicating that individuals under high-elaboration conditions made their judgments on the basis of metacognitive difficulty whereas those under low-elaboration conditions based their judgments on the actual number of thoughts generated. Rothman and Hardin (1997) showed that metacognitive difficulty had greater negative impacts on the 
judgment of close friends than that of casual acquaintances. In a similar vein, Wänke and Bless (2000) found that individuals under greater accuracy motivation evaluated a target product less positively after processing difficult-to-process than easy-to- process product information regardless of its argument quality. Tormala et al. (2007) also found that the number of unrequested counter-arguments spontaneously brought to mind could mediate the negative impact of metacognitive difficulty in generating supporting arguments on judgments under greater cognitive resources.

In contrast to the above-mentioned observations that judgments based on metacognitive difficulty are more resource demanding, individuals' reliance on metacognitive difficulty in making judgments has long been considered a heuristic process (for a review, see Greifeneder, Bless, and Pham 2010). Rothman and Schwarz (1998), for example, interpreted the effect of metacognitive difficulty found for those who rated themselves as being less vulnerable to heart disease as evidence for a heuristic process. Likewise, Grayson and Schwarz (1999) indicated that women who had been asked to assume that sexual assault might happen to any women considered themselves more (less) vulnerable to sexual assault after recalling eight (three) risk-increasing behaviors they had personally engaged in. Aarts and Dijksterhuis (1999) also indicated that individuals under low accuracy motivation underestimated the frequency of their past bicycle use after recalling eight rather than three instances. And Ruder and Bless (2003) found that individuals in a positive mood (vs. a negative mood) evaluated a target object more positively after thinking of many rather than a few supporting arguments. Consistent with the dual-process models of judgments (Chen and Chaiken 1999: Petty and Wegener 1999), all of the findings suggest that individuals under low processing motivation engage in heuristic processing. drawing on metacognitive difficulty whereas those under high processing motivation adopt systematic information processing, relying on the content of information brought to mind at the time of judgments.

According to Greifeneder and Bless (2007), however, the effect of metacognitive difficulty on judgments may involve a two-stage backward inference process: (1) awareness of processinduced metacognitive difficulty and (2) interpretation of what metacognitive difficulty implies to judgments. Drawing on the two-stage backward inference process, the current research posits that the two-stage backward inference process requires individuals to possess a certain level of cognitive resources to begin with (e.g.. accuracy motivation, cognitive load, knowledge, expertise) because individuals who lack such cognitive resources may not be able to engage in generating judgment-relevant implications of experienced metacognitive difficulty in retrieving or processing information. Alter et al. (2007). for example, demonstrated that individuals 
often interpreted metacognitive difficulty as a cue to deploy additional cognitive resources, which resulted in greater reliance on systematic information than peripheral cues when evaluating the attractiveness of a target product. The findings indicated that individuals exhibited lesser use of representative heuristic and relied more on systematic information than peripheral cues after having experienced metacognitive difficulty. suggesting that metacognitive difficulty activated analytic reasoning and in-depth information processing. Taken together, the current research hypothesizes that individuals with greater cognitive resources available are more likely than those with lack of cognitive resources to make their judgments based on the reflection of metacognitive difficulty in addition to the content of information generated.

\subsection{Conceptualization of Perceived Fit Between Self-Regulatory Orientation and Construal-Level as Cognitive Resources}

According to Avnet and Higgins (2003) and Higgins et al. (2003), individuals experience regulatory fit when their self-regulatory orientations are in line with their strategies adopted for goal pursuit. Because the perceived regulatory fit makes individuals feel right about what they are doing and this experience of correctness and importance transferred the subsequent evaluation of target objects, increasing the perceived value of their final decision beyond the value of the outcomes. Lee and Aaker (2004), for example, indicated that individuals under a loss versus non-loss frame evaluated a prevention appeal more positively whereas those under a gain versus a non-gain frame evaluated a promotion appeal more favorably. Also, Mogilner, Aaker, and Pennington (2008) found that individuals evaluated prevention-framed products more positively when their purchase decisions were made in the near future whereas they evaluated promotion-framed product more favorably when their decisions were made in the distant future. In a related vein, regulatory focus theory (Higgins 1997, 2000) posits that prevention-focused individuals tend to regulate themselves in order to attain safety and security whereas promotion-focused individuals appear to regulate themselves in order to achieve performance and advancement. Lee. Aaker, and Gardner (2000), for example, showed that independent individuals placed greater weight on promotion-related benefits whereas interdependent individuals placed more emphasis on prevention-related benefits.

On the other hand, prior research on regulatory fit indicated that perceived regulatory fit intensified individuals motivation (Idson, Liberman, and Higgins 2004), increased cognitive resources invested in judgment tasks (Aaker and Lee 2001: Worthy, Maddox, and Markman 2007). and resulted in greater cognitive persistence (Hong and Lee 2005). That is, individuals who 
perceived regulatory fit were more likely to invest their full cognitive resources into processing both the content of information and metacognitive difficulty experienced while processing information. Building upon these arguments, the current research varies the level of cognitive resources available by way of perceived fit or non-fit between participants' self-regulatory orientation and construal level. Drawing on the two-stage backward inference process (Greifeneder and Bless 2007) and consistent with Tormala et al. (2002), the current research anticipates that product evaluations will be more positive when individuals under perceived regulatory-construal level fit are asked to think of a few rather than many positive reasons. In contrast, product evaluations will be more positive when individuals under perceived nonfit between regulatory orientation and construal level are asked to think of many rather than a few positive reasons.

\section{Experiment 1}

The aim of Experiment 1 was to test the research hypothesis that individuals with greater cognitive resources available would be more likely than those with lack of cognitive resources to make their judgments based on the reflection of metacognitive difficulty in addition to the content of information generated. Following Higgins et al. (1994), the current experiment developed a self-reflective essay writing task in which participants were asked to describe how their personal standards (described as either "hopes-and-aspirations" or "duties-andobligations") had changed as they had matured. Experiment 1 also varied the level of perceived fit between participants self-regulatory orientation and temporal construal to induce a different level of cognitive resources to be invested into a judgment task.

\subsection{Design and Participants}

A 2 (regulatory focus: prevention- or promotionfocus) $\times 2$ (temporal orientation: a near or a distant future frame) $\times 2$ (requested number of reasons: one or 10 reasons) between-subjects design was employed in the current experiment. The first two factors, regulatory focus and temporal orientation, were combined to create perceived fit between regulatory orientation and temporal construal because no significant interaction was found $(F<1)$. Regulatory focus was manipulated by asking participants to describe their personal standards, either duties-and-obligations (a prevention-focused goal) or hopes-and-aspirations (a promotionfocused goal), from their high school years and how their personal standards had changed since then. Temporal orientation manipulation involved having participants consider the purchase of a target product either in the next week (a near future frame) or in a year or two from now (a 
distant future frame). The requested number of reasons was manipulated by asking participants to think of either one (easy to think of) or 10 (difficult to think of) good reasons to buy a target product. One hundred and five undergraduate students (59 males, 46 females, $\left.M_{\text {age }}=20.3\right)$ recruited from a large midwestern private university in the U.S. participated in this experiment in return for $\$ 10$.

\subsection{Procedure and Measures}

A stimulus material started with the target ad which contained the following message: "No more if onlys: Mixing leading-edge technology with the latest digital imaging system. the Sony MiniDV Handycam® gives you many reasons to buy. Can you think of one (ten) good reason(s) to buy it?" Then, prior to the reason generation task, temporal framing was varied in a question on the next page: "Suppose, for the moment, in the next week (in a year or two from now) you are considering the purchase of the Sony MiniDV Handycam. Can you think of one (ten) good reason(s) to buy it?" Upon arrival, participants were first randomly assigned to regulatory focus manipulation in which they were asked to describe either their duties-and-obligations or hopes-and-aspirations. On the next page participants were asked to consider the purchase of the target product either in the next week or in a year or two from now. Parti- cipants were then asked to generate the requested number of good reasons to buy the target product. No time limit was given to perform this task. After participants wrote down reasons, they evaluated the target product based on twelve, 7-point bipolar adjective items including dislike-like, unfavorable-favorable, unreliable-reliable, low-high quality, unattractiveattractive, not durable-durable, poor-good performance, undesirable-desirable, outdated-cuttingedge technology, poor-good value, commonadvanced, bad-good. The items were averaged to form a reliable product evaluation index ( $a=$ 89). Participants were then asked to report how difficult and how annoying it was to generate reasons to buy Sony MiniDV Handycam on 7-point scale items. These two items were averaged to form a reliable metacognitive difficulty index $(a=87)$. Next, participants reported the level of cognitive resources invested on the basis of the level of involvement they put forth into the judgment task.

\subsection{Results and Discussion}

As shown in Table 1, a 2 (perceived fit between regulatory-temporal orientation) $\times 2$ (the requested number of reasons) ANOVA indicated that participants perceived generating 10 good reasons ( $M=4.8$ ) to be more difficult than one reason $(M=3.4: F(1,101)=$ 22.14, $p<.001)$. The analysis also showed that participants who perceived the fit between 
$\langle$ Table 1〉 Experiment 1: Treatment Means

\begin{tabular}{|c|c|c|c|c|}
\hline & \multicolumn{4}{|c|}{$\begin{array}{l}\text { Regulatory Orientation-Temporal Construal Fit } \\
\text { (The Availability of Cognitive Resources) }\end{array}$} \\
\hline & \multicolumn{2}{|c|}{$\begin{array}{c}\text { Fit } \\
\text { (High) }\end{array}$} & \multicolumn{2}{|c|}{$\begin{array}{l}\text { Nonfit } \\
\text { (Low) }\end{array}$} \\
\hline & One Reason & Ten Reasons & One Reason & Ten Reasons \\
\hline Product Evaluation & 5.7 & 5.1 & 5.0 & 5.7 \\
\hline Metacognitive Difficulty & 3.2 & 4.7 & 3.6 & 4.9 \\
\hline Cognitive Resources Invested & 4.8 & 4.9 & 4.3 & 4.4 \\
\hline$N$ & 27 & 25 & 25 & 28 \\
\hline
\end{tabular}

their regulatory and temporal orientation $(M=$ 4.9) were more likely to exert greater cognitive resources into their judgment task than those who perceived a non-fit $(M=4.3: F(1,101)$ $=5.26, p<.05)$. No other significant effects were found, demonstrating both manipulations were successful.

A 2 (perceived fit between regulatory-temporal orientation) $\times 2$ (the requested number of reasons) ANOVA was performed on the product evaluation index. As Table 1 indicates, the analysis yielded only a significant two-way interaction $(F(1,101)=16.66, p<.01)$. The analysis of simple effects indicated that participants under the perceived fit evaluated the target product more favorably when asked to think of one reason $(M=5.7)$ than 10 reasons $(M=5.1: F(1,101)=9.98, p<.001)$. Participants under the perceived non-fit, however, evaluated the target product more favorably after generating 10 reasons $(M=5.7)$ than one reason $(M=5.0: F(1,101)=6.82 . p<$ $.05)$. The findings from Experiment 1 successfully demonstrated that participants made their judgments based on metacognitive difficulty when they had substantial cognitive resources, replicating Tormala et al's (2002). Also, the findings provided initial empirical support for the two-stage backward inference process such that participants who lacked cognitive resources were not able to draw further inferences regarding judgment-relevant implications of experienced metacognitive difficulty in retrieving or processing information.

\section{Experiment 2}

The findings of Experiment 1 demonstrated that the availability of cognitive resources enabled participants to make further reflections on metacognitive difficulty, resulting in less positive product evaluations. The primary objective of Experiment 2 was to replicate and generalize the findings from Experiment 1 by using a different target product category (i.e., automobile) and conceptualizing perceived regulatory-construal- 
level fit in a different manner (i.e.. perceived fit between self-construal and the type of product benefit appeal). According to regulatory focus theory (Higgins 1997, 2000), preventionfocused individuals are likely to regulate their attitudes and behaviors to attain safety and security whereas promotion-focused individuals are likely to regulate their attitudes and behaviors to attain performance and advancement. For example, Lee et al. (2000) demonstrated that individuals with a dominant independent self-construal were likely to place greater emphasis on promotion-focused information whereas those with a dominant interdependent selfconstrual were likely to place more weight on prevention-focused information. Experiment 2 thus decided to conceptualize perceived fit between self-regulatory orientation and construallevel as perceived fit between self-construal and the type of product benefit appeal.

\subsection{Design and Participants}

A 2 (self-construal: independent vs, interdependent) $\times 2$ (type of product benefit appeal: performance vs. safety) $\times 2$ (the requested number of reasons: one vs. 10 reasons) betweensubjects design was employed in Experiment 2. Again, the first two factors, self-construal and types of product benefit appeal, were combined to create perceived fit between self-construal and types of product benefit appeal because no significant interaction was found $(F<1)$. The self-construal factor was measured on the basis of a battery of 30 self-construal items adopted from Singelis's (1994). As in the previous experiment, the requested number of reasons was manipulated by asking participants to think of either one (easy to think of) or 10 (difficult to think of) good reasons to buy a target product. The manipulation of type of product benefit appeal involved addressing either safety ("A checklist full of safety features") or performance ("A new passion for performance driving") dimension of a target car in the ad. One hundred and thirty-six undergraduate students (59 males, 77 females, $M_{\text {age }}=20$ ) recruited from a large mid-western private university in the U.S. participated in this experiment in return for $\$ 10$.

\subsection{Procedure and Measures}

A target ad contained the following advertising message: "A checklist full of safety features (A new passion for performance driving). There are many reasons to buy the Lexus IS 300 sedan. Can you think of one (ten) good reason(s) to buy it?" The ad was varied to manipulate the type of product benefit appeal (safety or performance) and the requested number of reasons (one or 10 reasons). After participants were asked to generate good reasons and to evaluate the target product, a battery of 30 self-construal measures adopted from Singelis's (1994) was administered for a mea- 
sured independent variable regarding participants' self-construal (interdependent vs. independent self-construal). Upon arrival, participants were first shown the target ad for the Lexus IS300 sedan with either performance or safety benefit appeal. On the next page, participants were asked to generate good reasons to buy the target product. After participants generated reasons, they were then asked to evaluate the target product on the basis of thirteen, 7-point bipolar adjective items including dislike-like, unfavorable-favorable, unreliable-reliable, lowhigh quality, not durable-durable, poor-good performance, undesirable-desirable, outdatedcutting edge technology, common-advanced, badgood, not impressive-impressive, not valuablevaluable, simple-sophisticated. These items were averaged to form a reliable product evaluation index $(a=.91)$. Next, participants completed the manipulation checks identical to the previous experiment, self-construal measures, and demographic items. Factor analysis reduced 30 self-construal items to 14 items ( $1=$ strongly disagree, $7=$ strongly agree). These 14 items were averaged to form a reliable self-construal scale $(a=.81)$. Participants were then split on the median of the scale (median $=4.7$ ) such that participants who scored above the median of the self-construal scale were categorized as independent self-construals $(N=$ 68) and those who scored below the median were categorized as interdependent self-construals $(N=69)$. Last, participants were debriefed and dispersed.

\subsection{Results and Discussion}

A 2 (perceived fit between self-construal and type of product benefit appeal) $\times 2$ (the requested number of reasons) ANOVA revealed a significant main effect of the requested number of reasons on the metacognitive difficulty index ( $M_{\mathrm{ONE}}$ REASON $=3.6$ vs, $M_{\text {TEN }}$ REASONS $=5.6: F(1,133)=61.38, p<.001)$. suggesting that participants experienced greater metacognitive difficulty after generating 10 good reasons than one reason. Also, the analysis indicated that participants under the perceived fit ( $M=3.9)$ were likely to invest greater level of cognitive resources into their judgment task than those under the perceived non-fit $(M=3.4, F(1,133)=4.42, p<.05)$. Again, no other significant effects were found for the manipulation checks.

As Figure 1 shows, a significant interaction between perceived fit and the requested number of reasons emerged $(F(1,133)=30.80, p<$ $.001)$. The analysis of simple effects indicated that participants under the perceived fit evaluated the target car more favorably after generating one reason $(M=5.9)$ than 10 reasons $(M=5.0: F(1,133)=13.83, p<$ $.001)$. In contrast, the opposite was true when they perceived a non-fit between their selfconstrual and type of product benefit appeal $\left(M_{\text {ONE REASON }}=5.2\right.$ vs. $M_{\text {TEN REASONS }}=6.0$ : 


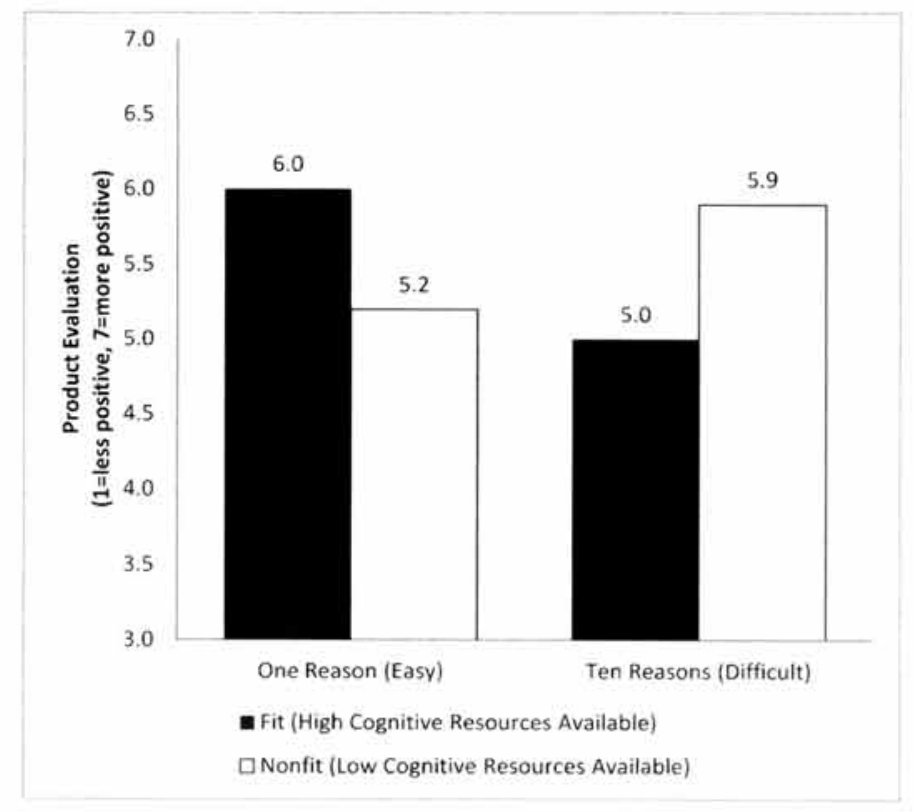

〈Figure 1〉 Experiment 2: Product Evaluation

$F(1,133)=17.02, p<.001)$. These results demonstrated that participants' judgments were based on metacognitive difficulty with which reasons came to mind when individuals perceived greater fit between their self-construal and type of product benefit appeal. Because the perceived fit was shown to increase the level of cognitive resources to be invested into their judgment task, participants under high cognitive resources were more likely than those under low cognitive resources to draw on metacognitive difficulty when making their product evaluations. Consistent with Experiment 1, the findings documented further empirical evidence for the two-stage backward inference process and the reliance on metacognitive difficulty as a systematic process.

\section{General Discussion and Implications}

The present research documents additional empirical evidence for the proposition that individuals with substantial cognitive resources are more likely than those with lack of cognitive resources to draw on metacognitive difficulty when making judgments, suggesting that judgments based on metacognitive difficulty often involve a systematic information processing. The findings of two laboratory experiments show that the target products are evaluated more positively when individuals perceive a greater level of fit between self-regulatory orientation and temporal construal (Experiment 1). and between self-construal and type of product 
benefit appeal (Experiment 2). Given the twostage backward inference process (Greifeneder and Bless 2007), the findings imply that individuals with substantial cognitive resources are more likely to draw on metacognitive difficulty because substantial cognitive resources enable them to possess both the content of information generated and judgment-relevant implications of metacognitive difficulty experienced. In contrast, individuals who lack such cognitive resources may not be able to interpret the meanings associated with experienced metacognitive difficulty in retrieving or processing information (e.g.. Lee and Park 2012).

The findings of this research contribute to the current debate about the role of cognitive resources in determining the effects of metacognitive difficulty on judgments. Unlike the findings in favor of the ease of retrieval as a judgmental heuristic (e.g.. Dijksterhuis et al. 1999: Grayson and Schwarz 1999: Rothman and Schwarz 1998: Ruder and Bless 2003), the current research provides further evidence for Tormala et al.'s (2002) prediction that a retrieval ease effect is found when participants cognitive resources are substantial, and a content effect is observed when cognitive resources are relatively limited. According to Tybout et al.'s (2005) information accessibility hypothesis, individuals are most likely to draw on metacognitive difficulty when they possess a moderate level of cognitive resources about a target product. In contrast, participants with limited ac- cessibility to target-relevant information, they are not able to make further reflections on metacognitive difficulty experienced, making their judgments based on the content of information generated.

Consistent with prior research on the relationship between regulatory fit and cognitive resources (Aaker and Lee 2001: Hong and Lee 2005: Idson et al. 2004: Worthy et al. 2007). the current research also documents further empirical evidence for the relationship between regulatory-construal level fit and cognitive resources, such that perceived regulatory-construal level fit can increase individuals' willingness to invest cognitive resources into their judgment tasks. Nevertheless, further research on this topic seems warranted because the use of student sample and a limited variety of product categories tested may limit the generalizeability of the findings.

Consumers are oftentimes encouraged or motivated to think of many positive reasons that they prefer or switch to a particular brand (e.g., MSN's "there are many reasons" and Apple's "switch" ad campaign) regardless of whether a target brand offers product benefits that are compatible with their self-regulatory orientation. Suppose a marketer tries to sell a Volvo car to a group of consumers who are safety-oriented. In most of these circumstances, a marketer tends to advertise as many similar benefits (e.g.. airbags, ABS, run-flat tire, sturdy body. warranty, etc.) as possible to make the car 
attractive to those consumers. Based on the findings from the current research, however, the persuasive attempts of this kind may backfire because consumers are likely to base their judgments on metacognitive difficulty. Because of the high-involvement nature of car purchasing, these safety- or prevention-focused consumers are likely to possess substantial cognitive resources for processing product benefits and reflecting further upon the overall judgmental process, having them thinking of a lot of reasons may increase their reliance on metacognitive difficulty, rendering their judgments less positive. On the other hand, if the same marketer tries to sell a Volvo car to a group of consumers who are performance-oriented, it may be more effective to provide as many benefits as possible because perceived nonfit can usurp cognitive resources available that promotionfocused consumers can invest into reflecting further upon the judgment-relevant implications of metacognitive difficulty, resulting in judgments based on product benefits processed.

〈Recieved May 08. 2012〉

〈Revised May 22. 2012〉

〈Accepted May 29. 2012〉

\section{References}

Aaker, Jennifer L. and Angela Y. Lee (2001), ". "I" Seek Pleasures and "We" Avoid
Pains: The Role of Self-Regulatory Goals in Information Processing and Persuasion," Journal of Consumer Research, 28 (June), $33-49$.

Aarts, Henk and Ap Dijksterhuis (1999), "How Often Did I Do It? Experienced Ease of Retrieval and Frequency Estimates of Past Behavior," Acta Psychologica, 103, 77-89. Chen, Serena and Shelly Chaiken (1999), "The Heuristic-Systematic Model in Its Broader Context," in Dual-Process Theories in Social Psychology, ed. Shelly Chaiken and Yaacov Trope, New York. NY: The Guilford Press, 73-96.

Dijksterhuis, Ap, C. Neil Macrae. Geoffrey Haddock (1999), "When Recollective Experiences Matter: Subjective Ease of $\mathrm{Re}^{-}$ trieval and Stereotyping," Personality and Social Psychology Bulletin, 25 (June), 76068.

Grayson, Carla E. and Norbert Schwarz (1999). "Beliefs Influence Information Processing Strategies: Declarative and Experiential Information in Risk Assessment," Social Cognition, 17, 1-18.

Greifeneder, Rainer and Herbert Bless (2007). "Relying on Accessible Content versus Accessibility Experiences: The Case of Processing Capacity," Social Cognition, 25 (6), 853-81.

Greifeneder, Rainer, Herbert Bless, and Michel Tuan Pham (2010), "When Do People Rely on Affective and Cognitive Feelings in 
Judgment? A Review," Personality and

Social Psychology Review, 15 (2), 107-41. Higgins, E. Tory (1997), "Beyond Pleasure and Pain," American Psychologist, 52 (December). 1280-1300.

Higgins, E. Tory (2000), "Making a Good Decision: Value from Fit," American Psychologist. 55 (November), 1217-30.

Higgins, E. Tory. Lorraine Chen Idson. Antonio L. Freitas, Scott Spiegel, and Daniel C. Molden (2003), "Transfer of Value from Fit," Journal of Personality and Social Psychology, 84 (6), 1140-53.

Hong. Jiewen and Angela Y. Lee (2008), "Be Fit and Be Strong: Mastering Self-Regulation through Regulatory Fit," Journal of Consumer Research, 34 (February), 682-95.

Idson, Lorraine Chen, Nira Liberman, and E. Tory Higgins (2004), "Imagining How You'd Feel: The Role of Motivational Experiences from Regulatory Fit," Personality and Social Psychology Bulletin, 30 (July), 926-37.

Lee. Angela Y. and Jennifer L. Aaker (2004). "Bringing the Frame into Focus: The Influence of Regulatory Fit on Processing Fluency and Persuasion," Journal of Personality and Social Psychology, 86 (February). 205-18.

Lee, Angela Y., Jennifer L. Aaker, and Wendi Gardner (2000). "The Pleasures and Pains of Distinct Self-Construals: The Role of Interdependence in Regulatory Focus," Journal of Personality and Social Psychology, 78
(June), 1122-34.

Lee, Yoonjae and Kiwan Park (2012), "The Metacognitive Influence of Color on Product Attitude: The Case for Red and Its Conceptual Relation to Sexual Attractiveness," Journal of Korean Marketing Association, 27 (March), 135-60.

Menon, Geeta and Priya Raghubir (2003), "Ease of Retrieval as an Automatic Input in Judgments: A Mere-Accessibility Framework?" Journal of Consumer Research, 30 (September), 230-43.

Mogilner, Cassie, Jennifer L. Aaker, and Ginger Pennington (2008), “Time Will Tell: The Distant Appeal of Promotion and Imminent Appeal of Prevention," Journal of Consumer Research, 34 (February), 670-81.

Petty, Richard E. and Duane T. Wegener (1999), "The Elaboration Likelihood Model: Current Status and Controversies," in DualProcess Theories in Social Psychology, ed. Shelly Chaiken and Yaacov Trope. New York, NY: The Guilford Press, 41-72.

Rothman, Alexander J. and Curtis Hardin (1997). "Differential Use of the Availability Heuristic in Social Judgment," Personality and Social Psychology Bulletin, 23, 123-38.

Rothman. Alexander J. and Norbert Schwarz (1998), "Constructing Perceptions of Vulnerability: Personal Relevance and the Use of Experiential Information in Health Judgments," Personality and Social Psychology Bulletin, 24 (October). 1053-64. 
Ruder, Markus and Herbert Bless (2003), "Mood and the Reliance on the Ease of Retrieval Heuristic," Journal of Personality and Social Psychology, 85 (July), 20-32.

Schwarz, Norbert (1998), "Accessible Content and Accessibility Experiences: The Interplay of Declarative and Experiential Information in Judgment," Personality and Social Psychology Review, 2 (2), 87-99.

Schwarz, Norbert (2004), "Metacognitive Experiences in Consumer Judgment and $\mathrm{De}^{-}$ cision Making." Journal of Consumer Psychology, 14 (4), 332-48.

Schwarz, Norbert, Herbert Bless, Fritz Strack. Gisela Klumpp, Helga Rittenauer-Schatka. and Annette Simons (1991), "Ease of Retrieval as Information: Another Look at the Availability Heuristic," Journal of Personality and Social Psychology, 61 (August), 195-202. Singelis, Theodore M. (1994), “The Measurement of Independent and Interdependent SelfConstruals," Personality and Social Psychology Bulletin, 20 (5), 580-91.

Tormala, Zakary L., Carlos Falces, Pablo Briñol, and Richard E. Petty (2007), "Ease of Retrieval Effects in Social Judgment: The Role of Unrequested Cognitions," Journal of Personality and Social Psychology, 93 (2), 143-57.

Tormala, Zakary L., Richard E. Petty, and Pablo Briñol (2002), "Ease of Retrieval Effects in Persuasion: A Self-Validation Analysis," Personality and Social Psychology
Bulletin, 28 (December), 1700-12.

Tybout, Alice M., Brian Sternthal, Prashant Malaviya, Georgios A. Bakamitsos, and $\mathrm{Se}^{-}$ Bum Park (2005), "When Are Judgments Based on Product Benefits Versus Retrieval Ease?" Journal of Consumer Research. 32 (1), 76-85.

Worthy. Darrell A., W. Todd Maddox, and Arthur B. Markman (2007), "Regulatory Fit Effects in a Choice Task." Psychonomic Bulletin \& Review, 14 (6). 1125-32.

Wänke, Michaela and Herbert Bless (2000), "The Effects of Subjective Ease of Retrieval on Attitudinal Judgments: The Moderating Role of Processing Motivation," in The Message Within: The Role of Subjective Experience in Social Cognition and Behavior. ed. Herbert Bless and Joseph P. Forgas, Philadelphia, PA: Taylor \& Francis, 14361.

Wänke, Michaela, Gerd Bohner, and Andreas Jurkowitsch (1997), "There Are Many Reasons to Drive a BMW: Does Imagined Ease of Argument Generation Influence Attitudes?" Journal of Consumer Research. 24 (September), 170-77.

Wänke, Michaela, Norbert Schwarz, and Herbert Bless (1995), "The Availability Heuristic Revisited: Experienced Ease of Retrieval in Mundane Frequency Estimates," Acta Psychologica, 89 (June), 83-90. 